\title{
Supervised Immediate Postoperative Mobilization After Elective Colorectal Surgery: A Feasibility Study
}

\author{
Rose-Marie W. Thörn ${ }^{1}$ - Jan Stepniewski ${ }^{2} \cdot$ Hans Hjelmqvist ${ }^{3} \cdot$ Anette Forsberg $^{1} \cdot$ Rebecca Ahlstrand $^{3}$. \\ Olle Ljungqvist ${ }^{4}$
}

\begin{abstract}
Background Early mobilization is a significant part of the ERAS ${ }^{\circledR}$ Society guidelines, in which patients are recommended to spend $2 \mathrm{~h}$ out of bed on the day of surgery. However, it is not yet known how early patients can safely be mobilized after completion of colorectal surgery. The aim of this study was to evaluate the feasibility, and safety of providing almost immediate structured supervised mobilization starting 30 min post-surgery at the postoperative anesthesia care unit (PACU), and to describe reactions to this approach.

Methods This feasibility study includes 42 patients aged $\geq 18$ years who received elective colorectal surgery at Örebro University Hospital. They underwent a structured mobilization performed by a specialized physiotherapist using a modified Surgical ICU Optimal Mobilization Score (SOMS). SOMS determines the level of mobilization at four levels from no activity to ambulating. Mobilization was considered successful at SOMS $\geq 2$, corresponding to sitting on the edge of the bed as a proxy of sitting in a chair due to lack of space.

Results In all, $71 \%(n=30)$ of the patients reached their highest level of mobilization between the second and third hour of arrival in the PACU. Before discharge to the ward, $43 \%(n=18)$ could stand at the edge of the bed and $38 \%$ $(n=16)$ could ambulate. Symptoms that delayed advancement of mobilization were pain, somnolence, hypotension, nausea, and patient refusal. No serious adverse events occurred.

Conclusions Supervised mobilization is feasible and can safely be initiated in the immediate postoperative care after colorectal surgery.

Trial registration Clinical trials.gov identifier: NTC03357497.
\end{abstract}

\section{Introduction}

Rebecca Ahlstrand and Olle Ljungqvist share senior authorship for this publication.

Rose-Marie W. Thörn

rose-marie.wilnerzon-thorn@regionorebrolan.se

1 Department of Physiotherapy, Örebro University Hospital, Örebro, Sweden

2 Department of Anesthesiology and Intensive Care, Örebro University Hospital, Örebro, Sweden

3 Department of Anesthesiology and Intensive Care, Faculty of Medicine and Health, Örebro University, Örebro, Sweden

4 Department of Surgery, Faculty of Medicine and Health, Örebro University, Örebro, Sweden
Early postoperative mobilization is a well-established part of the multimodal evidence-based Enhanced Recovery After Surgery (ERAS) care pathway for surgical patients (http://www.erassociety.org/) [1]. Postoperative mobilization activities such as sitting, standing, and walking are key factors to minimize complications and reduce the length of hospital stay [2-4]. The most recent ERAS $^{\circledR}$ Society guidelines for colorectal surgery [1] recommend that patients should be mobilized out of bed on the day of surgery, at least by sitting in a chair for $2 \mathrm{~h}$, and for the rest of the stay in hospital aim to be out of bed for at least $6 \mathrm{~h}$ daily. Performing mobilization at the postoperative 
anesthesia care unit (PACU) can be perceived as risky, resource-intensive, and with barriers that can be perceived as to high for patients $[5,6]$. While early mobilization is advocated to prevent postoperative complications [7-9], there is lack of evidence how early after surgery the mobilization can be safely initiated and has not been investigated after colorectal surgery. The aim of this study was to evaluate the feasibility, and safety of providing immediate structured supervised mobilization to elective colorectal surgical patients in the PACU starting $30 \mathrm{~min}$ post-surgery, and to describe reactions to this approach.

\section{Material and methods}

\section{Design}

This study has its focus on the very immediate reactions to mobilization initiated as soon as possible at the PACU. The current report is part of a larger project to investigate the effects of this immediate intervention as opposed to the early mobilization initiated later on at the ward as suggested in ERAS programs. The main study is a randomized trial that is registered in Clinical Trials (NCT 03357497) where the effects of these two models of mobilization are compared with regard to different elements of recovery at different stages. In the current report, the effects and reactions to immediate mobilization are captured and discussed in detail.

Data were initially collected in a pilot study where 17 consecutive patients operated for elective colorectal surgery were subjected to immediate mobilization in December 2016 and January 2017. The pilot study revealed that immediate mobilization seemed feasible, since no safety issues could be identified. To broaden the material for the question raised in this study and to capture more variation in reactions, we also included the first 25 participants in the RCT randomized to the intervention group. No specific calculation was made to this sample size, but it felt to be reasonable in order to detect variations in how the patients were coping.

The inclusion criteria were age $\geq 18$ years and planned for elective major open or laparoscopic colorectal surgery at Örebro University Hospital. Patients were excluded if they were unable to understand written information or were unable to walk preoperatively. The setting was the PACU of the hospital, a unit with 13 recovery beds in an open floor environment.

Written consent was obtained from each participant. The study was approved by the Regional Ethics Board of Uppsala, Sweden (ref: 2017/223).

\section{Definitions}

\section{ERAS protocol}

All patients were admitted on the day before surgery and received standard care according to the standardized ERAS protocol (Table 1). The same standard preoperative information was given to all patients by the physiotherapist (Table 1). All patients were also informed that they would be subjected to immediate mobilization, at the PACU or at the ward.

\section{Anesthetic regime and immediate postoperative care}

Patients received standard anesthesia and analgesia care for colorectal surgery at our hospital (Table 1) including intraoperative prophylaxis for postoperative nausea and vomiting (PONV).

At the PACU standard patient monitoring was employed for all patients for at least an hour and thereafter until they met the discharge criteria (Table 1).

\section{Intervention}

A mobilization protocol based on the Surgical ICU Optimal Mobilization Score (SOMS) [10] was used to structure and evaluate the mobilization intervention. This score describes mobilization from none (0) to ambulating (4). In the present study, it was modified to describe mobilization of surgical patients in the PACU (Table 2). A specialized physiotherapist with 30 years of experience working with patients in intensive care and with major colorectal surgery was in charge of the mobilization intervention for all the participants. The physiotherapist alone performed all mobilization in bed and until sitting on the bedside. Any mobilization beyond this level was performed with the assistance of a nursing assistant.

Mobilization started 30 min after arrival in the PACU, after receiving a report from the PACU nurse and completion of assessment according to the safety criteria for advancing mobilization (Table 2) [11]. The patient was then mobilized at 30 min intervals with $30 \mathrm{~min}$ of rest between attempts during the hours 1,2,3, and 4 of arrival to the PACU. At each mobilization attempt, the patient was advanced as far as they were able to along the stepwise SOMS mobilization schedule while adhering to safety criteria $[10,11]$. This continued until the patient was discharged to the ward, or for a maximum of $4 \mathrm{~h}$. Since the patient was bedridden at the start of each mobilization, each attempt started with activity in bed (level 1). If physiologically stable, the patient was mobilized to sit at the bedside (level 2). This was used as proxy for being 
Table 1 The ERAS protocol for elective colorectal surgery: preadmission, preoperative, intraoperative, and postoperative procedures

\begin{tabular}{|c|c|}
\hline \multicolumn{2}{|l|}{ Preadmission } \\
\hline $\begin{array}{l}\text { Preoperative counseling and } \\
\text { patient education }\end{array}$ & Standardized oral and written information 2 weeks before surgery \\
\hline Nutritional assessment & $\begin{array}{l}\text { Evaluation for malnutrition (NRS 2002). If a need for dietary supplements is assessed, the patient receives a } \\
\text { starter pack of } 12 \text { nutritional drinks (Fresubin }{ }^{\circledR} \text { Protein Energy, SWE, } 200 \mathrm{ml} \text { ) }\end{array}$ \\
\hline Alcohol and tobacco & Tobacco and ethanol usage cessation before surgery \\
\hline Admission & Admission in the afternoon on the day before surgery \\
\hline Information from physiotherapist & $\begin{array}{l}\text { Standardized information about the aim to achieve postoperative daily mobilization goals (out of bed on the } \\
\text { day of surgery: at least by sitting in a chair for } 2 \mathrm{~h} \text { and for the rest of the stay in hospital: at least } 6 \mathrm{~h} \text { out } \\
\text { of bed daily) and instructions to perform a set of ten consecutive deep breaths three with a } 30-60 \text { pause } \\
\text { between each set at every hour with positive expiratory pressure device (PEP valve system } 22 \text {, Rium } \\
\text { Medical AB, Akersberga, Sweden) at a mid-expiratory pressure of } 10-15 \mathrm{~cm} \mathrm{H}_{2} \mathrm{O}\end{array}$ \\
\hline
\end{tabular}

\section{Preoperative}

Preoperative fasting

Carbohydrate treatment

Bowel preparation

Preemptive analgesia

Antibiotic prophylaxis

Thrombosis prophylaxis

Intraoperative

Anesthesia and pain management

Multimodal analgesia

Epidural anesthesia

Anesthesia induction

Anesthesia maintenance

PONV prophylaxis

Fluid treatment

Patient warming strategy

Drain and line management

Urinary catheter

Postoperative

Multimodal

Epidural

PONV treatment

Postoperative fluids

Nutrition and fluids

Discharge criteria from PACU
Food permitted until midnight; clear fluids until $2 \mathrm{~h}$ before surgery

Preoperative carbohydrate (preOp ${ }^{\circledR}$ Nutricia, NL, $400 \mathrm{ml}$ ) no later than 6 a.m. or 2 h before surgery

No routine bowel preparation

Paracetamol $1 \mathrm{~g}$ po. $1 \mathrm{~h}$ before surgery

Sulfometaxazol + trimetoprim 160/800 mg

Dalteparin 5000IE before 7 p.m. on the day before surgery

Parecoxib $40 \mathrm{mg}$ iv. clonidine $30-45 \mu \mathrm{g}$ iv, morphine $2-10 \mathrm{mg}$ iv. and repeat dose paracetamol $1 \mathrm{~g}$ iv. if long surgery

In laparotomy cases, EDA with bupivacaine $5 \mathrm{mg} / \mathrm{ml}+$ adrenalin $5 \mu \mathrm{g} / \mathrm{ml}$, continuous infusion or bolus. No EDA in laparoscopic cases

Fentanyl $2 \mu \mathrm{g} / \mathrm{kg}$, propofol $2 \mathrm{mg} / \mathrm{kg}$

Sevoflurane MAC 0.7-1.2 and intermittent fentanyl $1 \mu \mathrm{g} / \mathrm{kg}$

Betamethasone $4 \mathrm{mg}$ iv., ondansetron $4 \mathrm{mg}$ iv

Intraoperative crystalloid Ringer-Acetate infusion $4-6 \mathrm{ml} / \mathrm{kg} / \mathrm{h}$

Warmed infusions and hot air blanket

No routine postoperative nasogastric tube. No routine abdominal drains

Inserted in the operating room

Parecoxib $40 \mathrm{mg}$ iv, clonidine 30-45 $\mu \mathrm{g}$ iv. paracetamol $1 \mathrm{~g}$ iv. If inadequate, titrated doses morphine $2-5 \mathrm{mg}$ iv

If EDA is present, a shift to PCEA and change of anesthetic to ropivacaine $2 \mathrm{mg} / \mathrm{ml}+$ sufentanil $1 \mu \mathrm{g} / \mathrm{ml}$ Betamethasone 4-8 mg iv., ondansetron $4 \mathrm{mg}$ iv., droperidol 0.625-1.25 mg iv., metoklopramid $10 \mathrm{mg}$ iv Glucose $2.5 \% 500 \mathrm{ml}$ until next day if no oral intake and/or prolonged stay at PACU

Clear fluids offered at PACU for intake followed by nutritional drink $300 \mathrm{kcal}$

Respiration: unlabored breathing pattern with respiratory rate between 9 and 20; $\mathrm{SaPO}_{2}>95 \%$ or preoperative value. Restored coughing and swallowing function

Circulation: heart rate $>45$ and $<110$. Systolic blood pressure $>90$ and diastolic blood pressure $<199$. No new arrhythmia. No signs of myocardial ischemia. No active bleeding. Temperature $>36^{\circ} \mathrm{C}$. Pain: NRS $<4$

Neurology: Alert or preoperative status

National Early Warning Score $<4$ mobilized to sitting in chair due to lack of space for chairs. From there, the patient was mobilized to the standing position and taking steps in place (level 3). If the patient still remained physiologically stable, they were asked to ambulate $5-10 \mathrm{~m}$ (level 4). If the mobilization was interrupted due to symptoms of unsafe mobilization, the patient was brought back to bed to rest and a new mobilization attempt was performed starting at level 1 after a 30-min break, regardless of how many levels the patient had completed during the previous rounds. If the patient 
Table 2 Modified Surgical ICU Optimal Mobilization Score (SOMS), safety criteria, and barriers to mobilization

\begin{tabular}{|c|c|c|c|c|c|}
\hline SOMS & $\begin{array}{l}\text { Level } 0 \\
\text { No activity }\end{array}$ & $\begin{array}{l}\text { Level } 1 \\
\text { In-bed activity }\end{array}$ & $\begin{array}{l}\text { Level } 2 \\
\text { Sitting }\end{array}$ & $\begin{array}{l}\text { Level } 3 \\
\text { Standing }\end{array}$ & Level 4 Ambulating \\
\hline Definition & $\begin{array}{l}\text { Mobilization } \\
\text { was not } \\
\text { possible }\end{array}$ & $\begin{array}{l}\text { (Modified definition from original })^{a} \\
\text { Head end raised about } 30 \\
\text { degrees AND active lower leg } \\
\text { circulation exercise } 20 \text { reps, } 1 \text { set }\end{array}$ & $\begin{array}{l}\text { Sitting at } \\
\text { the } \\
\text { bedside } \\
\text { with/ } \\
\text { without } \\
\text { support }\end{array}$ & $\begin{array}{l}\text { Standing twice with/ } \\
\text { without support of } \\
\text { walking aid and } \\
\text { assistance of two } \\
\text { persons, and taking steps } \\
\text { in-place }\end{array}$ & $\begin{array}{l}\text { Ambulating } 5-10 \mathrm{~m} \text { with } \\
\text { walking aid and } \\
\text { assistance of two } \\
\text { persons, one on each } \\
\text { side of the patient }\end{array}$ \\
\hline \multirow{4}{*}{$\begin{array}{l}\text { Safety criteria } \\
\text { for advancing } \\
\text { active } \\
\text { mobilization }^{11}\end{array}$} & \multicolumn{5}{|c|}{ Percutaneous oxygen saturation $\geq 90 \%$} \\
\hline & \multicolumn{5}{|c|}{ Adequate blood pressure, fluid volume, and adequate pain control } \\
\hline & \multicolumn{5}{|c|}{$\begin{array}{l}\text { Postoperative vasopressor was not an absolute contraindication to mobilization, but the appropriateness of mobilization was } \\
\text { discussed with the clinical team including the anesthesiologist }\end{array}$} \\
\hline & \multicolumn{5}{|c|}{$\begin{array}{l}\text { If unsuccessful in achieving hemodynamic stabilization (abnormal electrocardiography, systolic blood pressure }<90 \mathrm{mmHg} \text { ) } \\
\text { or pain control, or there are signs of motor blockage due to epidural analgesia, do not advance }\end{array}$} \\
\hline
\end{tabular}

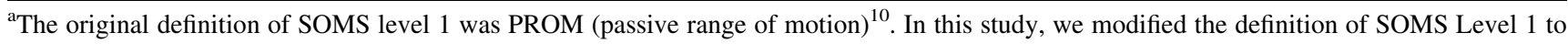
in-bed activity

reached SOMS level 4 and still remained in the PACU, a 60-min pause was allowed before mobilization began over again at level 1 . In addition to the above, the patients performed breathing exercises during each mobilization attempt to the above [12-14].

\section{Data collection}

Baseline demographics, perioperative data, and surgical data (Table 3) were extracted from the patient's medical record and from a prospectively maintained database, the ERAS $^{\circledR}$ Interactive Audit System (EIAS) [15]. Analgesia and pain were estimated using the numeric rating scale (NRS) of 0-10 [16] before and after each mobilization session [17]. Opioid consumption, PONV, and blood pressure management were also recorded.

Successful mobilization was defined as the patient being mobilized to sitting on the edge of the bed (as a proxy for being mobilized to sitting in a chair), standing, or ambulating (SOMS levels 2-4, respectively). Sitting on the edge instead of sitting on the chair as recommended by ERAS protocol was a compromise due to limitations in the PACU. Specific safety criteria (Table 2) were followed while advancing mobilization. Barriers hindering immediate advancement of mobilization and adverse events that occurred during the mobilization were recorded. Perioperative compliance with the ERAS colorectal protocol was recorded [18].

\section{Statistical analysis}

All data were analyzed with descriptive statistics using version 25 of IBM SPSS Statistics. Descriptive statistics for categorical variables were reported as frequency (percentage), while continuous or ordinal variables were presented as median (range or interquartile range).

\section{Results}

A total of 42 patients were included in the study. Demographic, perioperative, and surgical data are shown in Table 3. Two patients required conversion to an open surgery. Six patients had surgery lasting more than 240 min (rectal resection $n=4$, colonic resection $n=1$, other stoma procedures $n=1$ ).

All but one patient could be successfully mobilized at least to sitting, and $34(81 \%)$ was mobilized out of bed (standing/ambulating) (Table 4). Thirty patients (71\%) reached their highest level of mobilization being sitting to ambulating (SOMS 2-4) between the second and third hour of arrival in the PACU. Four patients $(10 \%)$ were able to be mobilized to sitting, standing, and ambulating in the first hour after arrival. Details are presented in Table 4 and Fig. 1. No severe adverse event occurred during mobilization of any of the patients. Somnolence $(n=28)$ and pain $(n=21)$ were the main barriers that hindered immediate advancement of mobilization.

Details of postoperative pain and perioperative opiate consumption are described in Table 5. The three patients requiring vasopressor treatment for hypotension when arriving at the PACU reached a highest SOMS level of 2 $(n=1)$ and 3-4 $(n=2)$, respectively. For all three patients, the vasopressor treatment could be discontinued before discharge. PONV was treated with ondansetron (Hameln, Germany); 20 patients received one dose, six patients received two doses, and three patients received three doses. One patient received a combination of ondansetron and betamethasone postoperatively. 
Table 3 Patients' demographic, perioperative, and surgical data $(n=42)$

\begin{tabular}{|c|c|}
\hline Female sex & $24(57)$ \\
\hline Age in years & $69(62-76)$ \\
\hline \multicolumn{2}{|l|}{ ASA group } \\
\hline 1 & $23(55)$ \\
\hline 2 & $13(31)$ \\
\hline 3 & $5(12)$ \\
\hline Unknown & $1(2)$ \\
\hline \multicolumn{2}{|l|}{ WHO score } \\
\hline 0 & $37(88)$ \\
\hline 1 & $5(12)$ \\
\hline Diabetes on medication & $8(19)$ \\
\hline $\mathrm{BMI}^{\mathrm{a}}$ & $25.5(23.1-29.1)$ \\
\hline Current smoker & $1(2)$ \\
\hline Alcohol usage & $1(2)$ \\
\hline \multicolumn{2}{|l|}{ Preoperative nutritional status ${ }^{b}$} \\
\hline Normal status & $24(57)$ \\
\hline Risk of malnutrition & $5(12)$ \\
\hline No, not assessed & $1(2)$ \\
\hline \multicolumn{2}{|l|}{ Presurgical therapy } \\
\hline Chemotherapy & $2(5)$ \\
\hline Radiotherapy & $10(24)$ \\
\hline Previous abdominal surgery & $27(64)$ \\
\hline Previous PONV ${ }^{\mathrm{c}}$ & $21(50)$ \\
\hline \multicolumn{2}{|l|}{ Type of surgery } \\
\hline Abdominoperineal resection & $6(14)$ \\
\hline Anterior resection of rectum & $3(7)$ \\
\hline Right hemicolectomy & $9(21)$ \\
\hline Left hemicolectomy & $3(7)$ \\
\hline Other stoma procedures & $8(19)$ \\
\hline Sigmoid resection & $8(19)$ \\
\hline Total colectomy & $4(9)$ \\
\hline Exploratory laparotomy & $1(2)$ \\
\hline \multicolumn{2}{|l|}{ Surgical approach } \\
\hline Open surgery & $25(60)$ \\
\hline Standard laparoscopic & $4(9)$ \\
\hline Robotic & $11(26)$ \\
\hline Approach through existing stoma & $2(5)$ \\
\hline Time of surgery, $\min ^{\mathrm{d}}$ & $174(137-215)$ \\
\hline Time anesthesia, $\min ^{\mathrm{e}}$ & $208(191-269)$ \\
\hline Total IV volume of fluids intraoperative $\mathrm{ml}^{\mathrm{f}}$ & $1000(525-1275)$ \\
\hline Core body temperature at the end of operation ${ }^{\mathrm{g}}$ & $35.95(35.6-36.4)$ \\
\hline
\end{tabular}

Table 3 continued

\begin{tabular}{l}
\hline Intraoperative blood loss, $\mathrm{ml}^{\mathrm{h}} \quad 50(0-100)$ \\
\hline $\begin{array}{l}\text { Values are reported as median (IQR) for ordinal or continuous vari- } \\
\text { ables and number (percentage) for categorical variables }\end{array}$ \\
ASA = American Society of Anesthesiologists $(1=$ normal healthy \\
patient, $2=$ mild systemic disease, $3=$ severe systemic disease); \\
WHO score = World Health Organization scale performance status \\
$(0=$ normal, $1=$ restricted in strenuous activity); PONV = postop- \\
erative nausea and vomiting; BMI = body mass index \\
${ }^{\mathrm{a}}$ missing $=5 ; \quad{ }^{\mathrm{b}}$ missing $=12 ; \quad{ }^{\mathrm{c}}$ unknown $=7 ;{ }^{\mathrm{d}}$ missing $=1 ;$ \\
${ }^{\mathrm{e}}$ missing $=15 ;{ }^{\mathrm{f}}$ missing $=1 ;{ }^{\mathrm{g}}$ missing $=16 ;{ }^{\mathrm{h}}$ missing $=2$
\end{tabular}

Perioperative compliance with the ERAS guideline elements was $81-100 \%$. Six patients with open surgery did not receive an epidural for the following reasons: last minute decision of change in surgical approach $(n=1)$, conversion to open surgery $(n=2)$, failed catheter placement $(n=2)$, and unknown $(n=1)$.

\section{Discussion}

We report that mobilization in the PACU starting $30 \mathrm{~min}$ after arriving is feasible, can be successful, and is safe for patients following elective colorectal surgery regardless of surgical approach. A structured mobilization procedure allowed us to mobilize all but one patient to sitting.

To our knowledge, this is the first study to evaluate the feasibility and safety of immediate mobilization after elective colorectal surgery. We report that it is feasible to mobilize already in PACU under the guidance of an experienced physiotherapist working with the nursing staff adding additional support and managing medical issues. Careful considerations were made to ensure patients' safety, including that ambulating always was performed with the assistance of two caregivers. This safety policy worked well, and no serious adverse events occurred. A concern when planning this study was how much the environment and the availability of human resources and appropriate equipment (for example, walking aids, anti-slip socks) would influence the feasibility of mobilization. We found these issues to be of no concern, and the environment was not a limiting factor for mobilization.

There were some factors delaying and affecting the level of mobilization. Medical factors included symptoms of remaining sedation and pain on arrival. Insufficient pain control contributed to mobilization delay, especially $1-2 \mathrm{~h}$ after arrival. Hypotension, dizziness, and nausea occurred mainly within the first $2 \mathrm{~h}$. Patient-related factors included unwillingness to mobilize. However, these factors did not prevent these patients from achieving their highest level of 
Table 4 Mobilization of patients in the PACU $(n=42)$

\begin{tabular}{|c|c|c|c|c|c|c|}
\hline Surgical approach & $\begin{array}{l}\text { Highest achieved } \\
\text { mobilization level }\end{array}$ & $\begin{array}{l}\text { Within } 1 \mathrm{~h} \text { in } \\
\text { PACU }(n)\end{array}$ & $\begin{array}{l}\text { Within } 2 \mathrm{~h} \text { in } \\
\text { PACU }(n)\end{array}$ & $\begin{array}{l}\text { Within } 3 \mathrm{~h} \text { in } \\
\text { PACU }(n)\end{array}$ & $\begin{array}{l}\text { Within } 4 \mathrm{~h} \text { in } \\
\text { PACU }(n)\end{array}$ & $\begin{array}{l}\text { Total } \\
\text { patient }(n)\end{array}$ \\
\hline \multirow[t]{4}{*}{ Open $(n=25)$} & $\begin{array}{l}\text { SOMS } 1 \text { (activity in } \\
\text { bed) }\end{array}$ & & & 1 & & 1 \\
\hline & SOMS 2 (sitting in bed) & 1 & 2 & 1 & & 4 \\
\hline & SOMS 3 (standing) & & 7 & 2 & 2 & 11 \\
\hline & SOMS 4 (ambulating) & 1 & 1 & 5 & 2 & 9 \\
\hline \multirow[t]{3}{*}{ Laparoscopic $(n=4)$} & SOMS 2 (sitting in bed) & & 2 & & & 2 \\
\hline & SOMS 3 (standing) & & 1 & & & 1 \\
\hline & SOMS 4 (ambulating) & & & & 1 & 1 \\
\hline \multirow[t]{2}{*}{ Robotic $(n=11)$} & SOMS 3 (standing) & 1 & 3 & & 1 & 5 \\
\hline & SOMS 4 (ambulating) & & 2 & 2 & 2 & 6 \\
\hline \multirow{2}{*}{$\begin{array}{l}\text { Approach through existing } \\
\text { stoma }(n=2)\end{array}$} & SOMS 2 (sitting in bed) & & 1 & & & 1 \\
\hline & SOMS 3 (standing) & & & 1 & & 1 \\
\hline
\end{tabular}

\section{Fig. 1 SOMS level}

achievement per time period in the PACU $(n=42)$. *Discharge from PACU $(n=11) * *$ discharge from PACU $(n=29)$

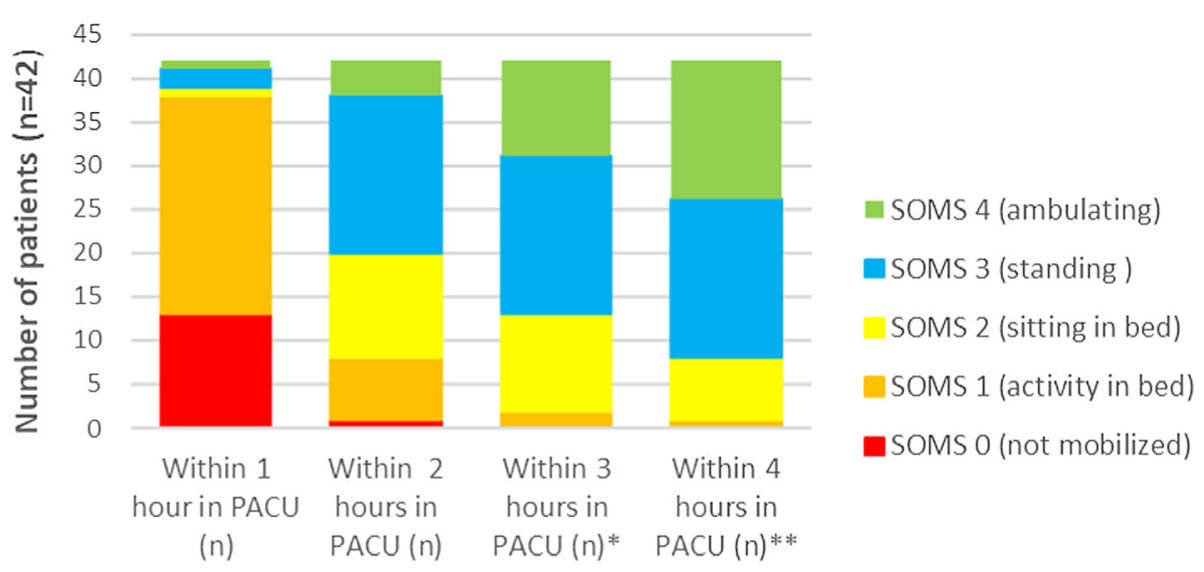

Time in PACU mobilization after optimizing pain control and nausea. Other limiting factors were related to the availability of staff. High workload and working schedules limited the assisting of ambulation for patients who underwent late afternoon surgery. Those factors created an intricate challenge and have to be considered in clinical practice.

The SOMS scale as a tool to structure the intervention process proved to be useful in two aspects. Firstly, its simplicity and clarity were advantageous, as it is straightforward, progressive, and intuitive. Secondly, it acted as a communication tool, which made it easy to convey the mobilization goal with the aim of increasing the patient's motivation as well to prepare the staff. Due to the structure of mobilization, with attempts being performed regularly every half hour, aiming for an exact time of mobilization as part of the nursing protocol made it easier to prepare the patient mentally but also helped the staff to ensure good logistics.

Symptoms of pain and nausea were assessed before each allotted time of mobilization, and patients could be given medication as needed. This procedure of assessing symptoms combined with pharmacological treatment if deemed necessary, synchronized with timed mobilization attempts by a team of dedicated professionals, proved to work well in enhancing immediate mobilization. Optimizing symptoms enabled patients to reach a higher SOMS level and reduce the mobilization delay. Only one patient could not be mobilized at all during its stay in the PACU, due to 


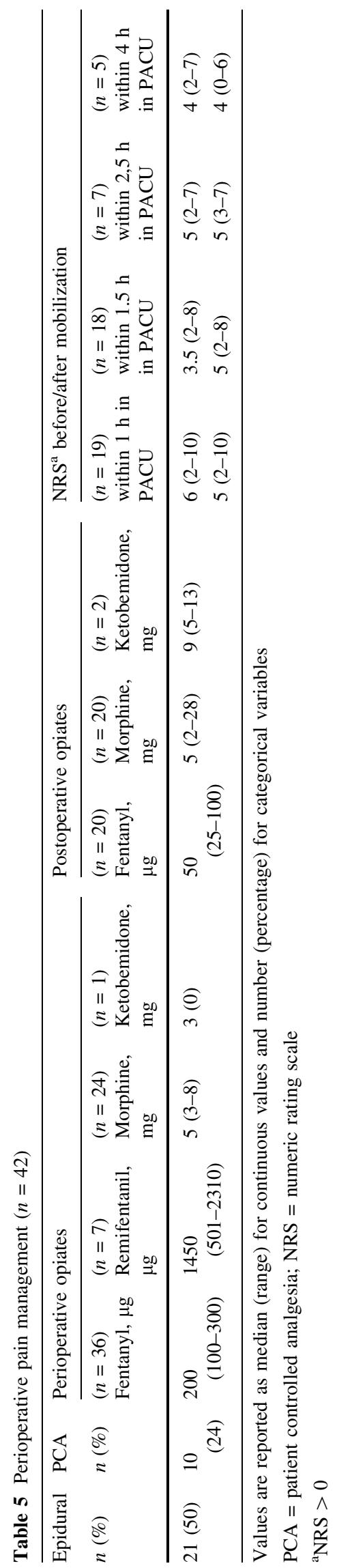

insufficient pain relief despite optimization. Physical issues such as low blood pressure and dizziness were handled immediately by competent staff nearby and appropriate aids.

A recent study showed that factors such as motivation and physical tiredness influence immediate mobilization in the PACU [5]. With our approach of repeated mobilization attempts and open communication and support between patient and physiotherapist, we found that the patients remained positive and engaged to further mobilization to try to reach higher levels of mobility despite barriers.

The results of this study suggest that starting structured mobilization is possible as early as 30 min after arrival in the PACU, when it is synchronized with assessment and management of symptoms as necessary. With this approach, most patients were standing and ambulating within 2-3 h after arrival. Our results confirm those of other studies recently showing that patients could be mobilized within $2 \mathrm{~h}$ after abdominal surgery [19] and within $4 \mathrm{~h}$ after pancreas and liver surgery [20, 21]. Although we suggest that mobilization could start as soon as $30 \mathrm{~min}$, the effects in patient's outcomes still need to be investigated. Fiori's study [22] showed that staff directed facilitation of mobilization on the day of surgery (after admission to the ward) did not improved outcomes. A recent $\mathrm{RCT}$, however, has shown that mobilization started within $2 \mathrm{~h}$ after abdominal surgery improved respiratory peripheral and arterial oxygenation [19].

Healthy patients, with minimal comorbidities, have been discharged on the same day or the next day after laparoscopic colorectal surgery [23] and this requires very early mobilization. For increased same day pathways, a requirement would consequently seem be an immediate mobilization in the PACU since it is feasible and safe.

Previous studies have shown that most patients with open colorectal surgery have more postoperative pain compared to minimally invasive approaches [24, 25]. Our use of multi-modal analgesia while minimizing the use of opioids is likely to have contributed to immediate mobilization for our patients undergoing colorectal surgery [26]. Among the six patients undergoing open surgery without an epidural in place, we found that the pain prevented four of them from managing a higher level of mobilization before adequate pain control was achieved.

\section{Strengths and limitations}

This was a pragmatic feasibility study in which mobilization after major surgery was stressed to its limits by initiating physical activity immediately on arrival at the PACU. The careful description of the mobilization protocol and safety routines allows replication in other settings. It could be argued that the small sample size and the lack of 
background population are limiting the generalizability of the results. However, the relatively uniform results regardless of variation in type of surgery, surgical approach, age, and sex suggest that this approach is adequate to initiate inclusion of more patients to test impacts on later recovery outcomes after colorectal surgery. Another limitation is the lack of patient-reported outcomes. This will be the focus in a future study.

In conclusion, this study suggests that it is feasible to initiate standardized mobilization as early as $30 \mathrm{~min}$ after arrival in the PACU after colorectal surgery. Forthcoming studies will address the question of whether this immediate mobilization also has a positive affect during the rest of the hospital stay and beyond.

Acknowledgements The authors would like to thank research nurses Katarina Axelzon and Maria Forsström for help with data collection, registration, and constant support. We are grateful for the help from nurse Ingrid Tinnfält and the personnel at the post-anesthesia care unit at the Department of Anesthesiology and Intensive Care, Örebro University Hospital.

Funding Open access funding provided by Örebro University. This study was supported by grants from the Research Committee of Örebro County Council and Örebro University Hospital Research Foundation, Sweden.

\section{Declarations}

Conflict of interest Olle Ljungqvist is the co-founder and current chairman of the ERAS ${ }^{\circledR}$ Society and founder and shareholder of Encare $\mathrm{AB}$, Sweden, which manages the ERAS ${ }^{\circledR}$ Interactive Audit System. Hans Hjelmqvist is member of the Swedish Chapter of the ERAS $^{\circledR}$ Society. The other authors declare that they have no conflict of interest.

Informed consent Informed consent was obtained from individual participants in this study.

Ethical approval Study was approved by the Regional Ethics Board of Uppsala, Sweden (ref: 2017/223).

Open Access This article is licensed under a Creative Commons Attribution 4.0 International License, which permits use, sharing, adaptation, distribution and reproduction in any medium or format, as long as you give appropriate credit to the original author(s) and the source, provide a link to the Creative Commons licence, and indicate if changes were made. The images or other third party material in this article are included in the article's Creative Commons licence, unless indicated otherwise in a credit line to the material. If material is not included in the article's Creative Commons licence and your intended use is not permitted by statutory regulation or exceeds the permitted use, you will need to obtain permission directly from the copyright holder. To view a copy of this licence, visit http://creativecommons. org/licenses/by/4.0/.

\section{References}

1. Gustafsson UO, Scott MJ, Hubner M, Nygren J, Demartines N, Francis N et al (2019) Guidelines for perioperative care in elective colorectal surgery: enhanced recovery after surgery $(\operatorname{ERAS}((\mathrm{R})))$ society recommendations: 2018. World J Surg 43(3):659-695

2. Nicholson A, Lowe MC, Parker J, Lewis SR, Alderson P, Smith AF (2014) Systematic review and meta-analysis of enhanced recovery programmes in surgical patients. $\mathrm{Br} \quad \mathrm{J}$ Surg 101(3): 172-188

3. Ljungqvist O, Scott M, Fearon KC (2017) Enhanced recovery after surgery: a review. JAMA Surg 152(3):292-298

4. Smart NJ, White P, Allison AS, Ockrim JB, Kennedy RH, Francis NK (2012) Deviation and failure of enhanced recovery after surgery following laparoscopic colorectal surgery: early prediction model. Colorectal Dis 14(10):e727-e734

5. Svensson-Raskh A, Schandl A, Holdar U, Fagevik Olsén M, Nygren-Bonnier M (2020) "I Have everything to win and nothing to lose": patient experiences of mobilization out of bed immediately after abdominal surgery. Phys Ther 100(12):2079-2089

6. Parry SM, Remedios L, Denehy L, Knight LD, Beach L, Rollinson TC et al (2017) What factors affect implementation of early rehabilitation into intensive care unit practice? A qualitative study with clinicians. J Crit Care 38:137-143

7. Dock W (1944) The evil sequelae of complete bed rest. J Am Med Assoc 125(16):1083-1085

8. Allen C, Glasziou P, Del Mar C (1999) Bed rest: a potentially harmful treatment needing more careful evaluation. Lancet 354(9186):1229-1233

9. Kehlet H, Dahl JB (2003) Anaesthesia, surgery, and challenges in postoperative recovery. Lancet 362(9399):1921-1928

10. Schaller SJ, Anstey M, Blobner M, Edrich T, Grabitz SD, Gradwohl-Matis I et al (2016) Early, goal-directed mobilisation in the surgical intensive care unit: a randomised controlled trial. Lancet 388(10052):1377-1388

11. Hodgson CL, Stiller K, Needham DM, Tipping CJ, Harrold M, Baldwin CE et al (2014) Expert consensus and recommendations on safety criteria for active mobilization of mechanically ventilated critically ill adults. Crit Care 18(6):658

12. Ambrosino N, Gabbrielli L (2010) Physiotherapy in the perioperative period. Best Pract Res Clin Anaesthesiol 24(2):283-289

13. Urell C, Emtner M, Hedenstrom H, Tenling A, Breidenskog M, Westerdahl E (2011) Deep breathing exercises with positive expiratory pressure at a higher rate improve oxygenation in the early period after cardiac surgery-a randomised controlled trial. Eur J Cardiothorac Surg 40(1):162-167

14. Fagevik Olsen M, Lannefors L, Westerdahl E (2015) Positive expiratory pressure-common clinical applications and physiological effects. Respir Med 109(3):297-307

15. Currie A, Soop M, Demartines N, Fearon K, Kennedy R, Ljungqvist $O$ (2019) Enhanced recovery after surgery interactive audit system: 10 years' experience with an international webbased clinical and research perioperative care database. Clin Colon Rectal Surg 32(1):75-81

16. Williamson A, Hoggart B (2005) Pain: a review of three commonly used pain rating scales. J Clin Nurs 14(7):798-804

17. Liang SS, Ying AJ, Affan ET, Kakala BF, Strippoli GF, Bullingham A et al (2019) Continuous local anaesthetic wound infusion for postoperative pain after midline laparotomy for colorectal resection in adults. Cochrane Database Syst Rev 10:CD012310

18. Elias KM, Stone AB, McGinigle K, Tankou JI, Scott MJ, Fawcett WJ et al (2019) The reporting on ERAS compliance, outcomes, and elements research (RECOvER) checklist: a joint statement by 
the $\operatorname{ERAS}((\mathrm{R}))$ and $\operatorname{ERAS}((\mathrm{R}))$ USA societies. World J Surg 43(1): $1-8$

19. Svensson-Raskh A, Schandl AR, Stahle A, Nygren-Bonnier M, Fagevik Olsen M (2021) Mobilization started within 2 hours after abdominal surgery improves peripheral and arterial oxygenation: a single-center randomized controlled trial. Phys Ther 101(5)

20. Fagevik Olsen M, Becovic S, Dean E (2021) Short-term effects of mobilization on oxygenation in patients after open surgery for pancreatic cancer: a randomized controlled trial. BMC Surg 21(1): 185

21. Savikko J, Vikatmaa L, Hiltunen AM, Mallat N, Tukiainen E, Salonen SM et al (2020) Enhanced recovery protocol in laparoscopic liver surgery. Surg Endosc

22. Fiore JF Jr, Castelino T, Pecorelli N, Niculiseanu P, Balvardi S, Hershorn O et al (2017) Ensuring early mobilization within an enhanced recovery program for colorectal surgery: a randomized controlled trial. Ann Surg 266(2):223-231
23. McKenna NP, Bews KA, Shariq OA, Habermann EB, Behm KT, Kelley SR et al (2020) Is same-day and next-day discharge after laparoscopic colectomy reasonable in select patients? Dis Colon Rectum 63(10):1427-1435

24. Brown D, McCormack B (2005) Developing postoperative pain management: utilising the promoting action on research implementation in health services (PARIHS) framework. Worldviews Evid Based Nurs 2(3):131-141

25. Burger JW, van 't Riet M, Jeekel J (2002) Abdominal incisions: techniques and postoperative complications. SJS 91(4):315-321

26. Simpson JC, Bao X, Agarwala A (2019) Pain management in enhanced recovery after surgery (ERAS) protocols. Clin Colon Rectal Surg 32(2):121-128

Publisher's Note Springer Nature remains neutral with regard to jurisdictional claims in published maps and institutional affiliations. 